\title{
Comparative study between insulin bolus regimen and glucose insulin infusion regimen on effectiveness of intraoperative blood glucose control in patients with type 2 diabetes mellitus undergoing non-cardiac surgery
}

\author{
Parthasarathy Arun ${ }^{1}$,Handattu Mahabaleswara Krishna ${ }^{2 *}$ \\ Resident Anaesthesiologist ${ }^{1}$, Professor ${ }^{2}$, Kasturba Medical College, Manipal, Manipal Academy of \\ Higher Education, India.
}

\begin{abstract}
Background: The surgical rates are comparatively greater among diabetic patients. Surgery, a period of stress, mandates fasting and anti-diabetic medications are skipped on the morning of the procedure. High blood glucose levels in the peri-operative period can lead to ischaemia, infection, acute kidney injury and electrolyte disturbances. Hence, control of blood glucose levels during the peri-operative period becomes important and there are various regimens described. We compared two of the existing regimens, intravenous insulin bolus and glucose insulin infusion regimen, for their effectiveness of intraoperative blood glucose control.

Method: In this randomized, prospective controlled study, 120 patients were enrolled with 60 patients in bolus group and 60 in infusion group. Capillary blood glucose was measured every hour during the intra-operative period. The primary outcome measure was proportion of patients in the target glucose levels between $100 \mathrm{mg} / \mathrm{dL}$ and $180 \mathrm{mg} / \mathrm{dL}$ and proportion of intra-operative surgery time (in minutes) during which patient was in the target range. Secondary outcome measure was serum potassium levels pre-operatively and postoperatively.
\end{abstract}

Results: The proportion of patients in the target range in the bolus group was 39 out of 60 as compared to 31 out of 60 in the infusion group $(\mathrm{P}=0.13)$. Also, proportion of intraoperative surgery time (in minutes) during which patient was in the target glycaemic range was $41.57 \%$ in bolus group when compared to $27.22 \%$ in the infusion group $(\mathrm{P}<0.05)$. No hypoglycaemic episodes were seen in any of the patients in the two groups.

Conclusion: As compared with infusion regimen, bolus regimen provides better glycaemic control measured in terms of target blood glucose levels and duration for which the patient remained in the target range.

Keywords: Diabetes mellitus; intraoperative glucose management

\section{Introduction}

The rate of surgeries in diabetic patients are more when compared to non-diabetic patients. ${ }^{1,2}$ Surgery under general or regional anaesthesia requires patient to be nil by mouth and glucose control medications omitted during this period. Glucose balance in the body can change due to metabolic disturbances occurring as a result of surgical stress.

Continuous high blood glucose levels can predispose to infection post-surgery, ischaemia of brain and impaired wound healing. ${ }^{3}$ It is also a risk factor for diabetic emergencies perioperatively, which can lead to negative

*Correspondence: Handattu Mahabaleswara Krishna E mail: hmkrishna20032002@yahoo.com

https://orcid.org/0000-0002-6106-4556

Received: $12 / 01 / 2019$

Accepted:01/06/2019

DOI: http://doi.org/10.4038/slja.v27i2.8400 prognostic consequences. Gastrointestinal derangements induced by drugs, stress and anaesthesia can cause nausea, vomiting and dehydration. Also, osmotic diuresis induced by hyperglycaemia leads to volume contraction. These place the patients at risk for acute kidney injury. Electrolyte imbalance because of altered glucose levels may increase the risk for arrhythmias. Hence, the metabolic profile of these patients who undergo surgery must be attended to perioperatively. ${ }^{3-6}$ The focus of these diabetic patients during surgery is prevention of either severely low or high blood sugar levels. ${ }^{5}$

There are many regimens that are described for perioperative blood glucose control each having its own advantages and disadvantages.

Intravenous insulin bolus is simple and reliable method for intra-operative glycaemic control and has been described by Poldermann et al. ${ }^{7}$ Intravenous insulin infusion along with glucose is another popular regimen for intra-operative blood glucose management. ${ }^{8}$ We compared the intra-operative glycaemic levels between insulin 
Krishna et al. Sri Lankan Journal of Anaesthesiology: 27(2):110-114(2019)

bolus regimen and glucose insulin infusion regimen. The aim was to compare the intraoperative capillary blood glucose levels between intravenous insulin bolus regimen and glucose insulin infusion regimen in diabetic patients. The primary objective was to compare the intra-operative capillary blood glucose levels in patients managed using insulin bolus and glucose insulin infusion regimen. The secondary objective was to compare the preoperative and postoperative serum potassium levels.

\section{Methods}

\section{Trial design}

This randomized, prospective study was a single centred trial conducted at Kasturba Hospital, Manipal, Karnataka, India, after obtaining approval of the Institutional Ethics Committee. The study was registered with Clinical Trials Registry India (CTRI/2017/12/011037).

\section{Eligibility criteria}

Patients with type 2 diabetes mellitus (diagnosed from pat history or medicine consultation) between 18 and 70 years with preoperative fasting blood glucose value $>150 \mathrm{mg} / \mathrm{dL}$ undergoing elective and emergency non-cardiac surgery of at least one hour were eligible for inclusion. Patients scheduled under local anaesthesia were not included. Patients with known history of cardiac, respiratory, renal, hepatic failure (either compensated or decompensated, as indicated by physician's evaluation and laboratory investigations), those having active infection or taking steroids (irrespective of whether on insulin therapy or not) were excluded. Also, pregnant females and those with serum potassium below the reference range $(<3.5 \mathrm{mmol} / \mathrm{L})$ were excluded.

\section{Randomization}

Consecutive patients scheduled for surgery were considered for enrolment. If eligible, the participants were randomized to one of the two groups, group bolus or group infusion in the study.

We used simple randomization method. Randomization was done with the help of a computer-generated table. The principal investigator generated the random allocated sequence, enrolled participants and assigned them to interventions. Patients and investigators were not blinded for the treatment.

\section{Interventions}

During preanaesthetic evaluation the patients were explained about the study methodology and written informed consent for participation in the study was obtained. Preoperative fasting instruction was nil per orally 8 hours for solids and 2 hours for clear fluids (based on local practice guidelines). All patients received acid aspiration prophylaxis with ranitidine $150 \mathrm{mg}$ and metoclopramide $10 \mathrm{mg}$ orally, on the previous night and on the morning of the surgery. All patients were advised to skip the oral hypoglycaemic agents or insulin injections on the day of surgery. Patients who had received long acting insulin on the night before the surgery were started on $5 \%$ dextrose in $0.9 \%$ saline infusion with insulin added based on morning value of fasting blood glucose. During fasting period, decision to start on $5 \%$ dextrose in $0.9 \%$ saline with neutralizing dose of insulin was as per the concerned anaesthesiology consultant in charge of the operating room. This fluid was discontinued in the operating room. The technique of anaesthesia depended upon the requirement of the patient as per the concerned anaesthesiology consultant in charge of the operating room. After arrival of the patient in the operating room and before induction of anaesthesia, random capillary blood glucose was measured (zero hour) and patients with values of $>150 \mathrm{mg} / \mathrm{dL}$ were included in the study. ${ }^{15}$ Subsequently capillary blood glucose was measured every hourly using glucometer (AccuChek Performa and Accu-Chek Performa glucose strips; error of measurement is $\pm 15 \%$ of the measured glucose values when compared with standard laboratory values) until the end of the surgery.

For the patients in group bolus, intravenous insulin - Monocomponent Human Insulin, biosynthetic r-DNA origin - Human Actrapid ${ }^{\circledR}$ (manufactured by Torrent Pharmaceuticals Ltd, Indrad 382 721, Dist: Mehsana, India, under license from Novo Nordisk India Private Ltd. Whitefield, Bangalore) was administered as given in Table $1 .^{7}$

This regimen was adapted from a trial published by Poldermann et al, converting $\mathrm{mmol} / \mathrm{L}$ to $\mathrm{mg} / \mathrm{dL}$ using multiplication factor 18 for conversion of $\mathrm{mmol} / \mathrm{L}$ to $\mathrm{mg} / \mathrm{dL}(1 \mathrm{mmol} / \mathrm{L}=18$ $\mathrm{mg} / \mathrm{dL}$ ), since the common mode of blood glucose measurement in our practice is in $\mathrm{mg} / \mathrm{dL}^{7}$ 
Krishna et al. Sri Lankan Journal of Anaesthesiology: 27(2):110-114(2019)

Table 1: Bolus insulin regimen

\begin{tabular}{|l|l|l|}
\hline $\begin{array}{l}\text { Glucose } \\
\text { measurement } \\
(\mathrm{mmol} / \mathrm{L})\end{array}$ & $\begin{array}{l}\text { Glucose } \\
\text { Measurement } \\
(\mathrm{mg} / \mathrm{dL})\end{array}$ & Insulin bolus (IU) \\
\hline $4-8$ & $72-144$ & - \\
\hline $8-9$ & $145-162$ & 2 \\
\hline $9-10$ & $163-180$ & 3 \\
\hline $10-11$ & $181-198$ & 4 \\
\hline $11-12$ & $199-216$ & 5 \\
\hline $12-13$ & $217-234$ & 6 \\
\hline $13-14$ & $235-252$ & 7 \\
\hline $14-15$ & $253-270$ & 8 \\
\hline $15-16$ & $271-288$ & 9 \\
\hline$>16$ & $>288$ & 10 \\
\hline
\end{tabular}

In an event of hypoglycaemia (blood glucose level $<70 \mathrm{mg} / \mathrm{dL}$ ), treatment was provided as bolus $100 \mathrm{ml} 5 \%$ dextrose in water (D5W) rapidly followed by repeat blood sugar level after 15mins. For the patients in group infusion, insulin was administered as infusion in $100 \mathrm{ml}$ of D5W taken in a burette set as given in Table $2 .{ }^{8}$ Before the start of infusion, $10 \mathrm{ml}$ of $5 \% \mathrm{D} 5 \mathrm{~W}+$ $1 \mathrm{IU}$ insulin was added and mixed well in the burette, flushed through the tubings and discarded. After measuring the blood glucose value, burette was filled with the $100 \mathrm{ml}$ of infusing solution and according to Table 2 insulin was added to the burette through the side arm using an insulin syringe. The blood glucose measurements were performed when the burette got empty at the end of one hour, using a glucometer.

Patients in both the groups received $0.9 \%$ saline to meet their fluid requirements. In both the groups, preoperative serum potassium value was compared with the postoperative serum potassium level measured after 1 hour of surgery.

\section{Outcome measures}

The primary outcome measures were (a) The proportion of patients in the target glucose levels between $100 \mathrm{mg} / \mathrm{dl}$ and $180 \mathrm{mg} / \mathrm{dl}$ and (b) proportion of intraoperative surgery time (in minutes) during which patient was in the target glucose range. The secondary outcome measure was serum potassium level.

\section{Sample size}

With $80 \%$ power and a difference of $10 \%$ of patients who could be maintained in the target glucose level $(100-180 \mathrm{mg} / \mathrm{dl})$ between the two studied regimens considered clinically significant, the sample size was estimated to be 360. Since the estimated sample size was relatively large with 360 patients, provision was made during the study design phase for two interim analyses i.e. when 120 patients and then 240 patients were enrolled. Interim analysis was done when two arms had a sample size of 60 each. It was found that the desired power and effect was achieved.

Table 2: Insulin infusion regimen

\begin{tabular}{|l|l|}
\hline $\begin{array}{l}\text { Blood glucose } \\
(\mathrm{mg} / \mathrm{dL})\end{array}$ & Treatment \\
\hline$<70$ & $\begin{array}{l}\text { Stop insulin infusion if any. Rapidly infuse } \\
100 \mathrm{ml} \text { of D5W. Measure blood sugar after } 15 \\
\text { min. }\end{array}$ \\
\hline 71 to 100 & Stop insulin if any. Infuse $100 \mathrm{ml} / \mathrm{h}$ of D5W \\
\hline 101 to 150 & $1 \mathrm{U}$ of insulin in100ml of D5W/h \\
\hline 151 to 200 & $2 \mathrm{U}$ of insulin in100ml of D5W/h \\
\hline 201 to 250 & $3 \mathrm{U}$ of insulin in100ml of D5W/h \\
\hline 251 to 300 & $4 \mathrm{U}$ of insulin in $100 \mathrm{ml}$ of D5W/h \\
\hline More than 300 & $\begin{array}{l}1 \mathrm{U} \text { of insulin for every } 1-50 \mathrm{mg}>100 \mathrm{mg} / \mathrm{dl} \text { in } \\
100 \mathrm{ml} \text { of NS/h }\end{array}$ \\
\hline
\end{tabular}

D5W - 5\% dextrose in water; NS - normal saline

\section{Statistical methods}

The proportion of patients in the target glucose levels between $100 \mathrm{mg} / \mathrm{dl}$ and $180 \mathrm{mg} / \mathrm{dl}$ and the proportion of intra-operative surgery time (in minutes) during which the patient was in the target range were analysed with Chi square test. The secondary outcome measure (serum potassium level compared between preoperative value and postoperative value within the group) was tested with $t$ test. Other statistical tests were used appropriately as required. SPSS 19 for Windows was used for statistical analysis.

\section{Results}

Patient characteristics and duration of surgery are given in Table 3. CONSORT flow chart is given in Figure 1. Comparison of proportion of patients in the target glycaemic range showed that 39 patients $(65 \%)$ in bolus group and 31 patients $(51.66 \%)$ in infusion group remained in the target glycaemic range in the intraoperative period. This was comparable $(\mathrm{P}=0.138$, Chi square test).

Table 3: Patient characteristics and duration of surgery

\begin{tabular}{|l|l|l|l|}
\hline & $\begin{array}{l}\text { Bolus group } \\
(\mathrm{n}=60)\end{array}$ & Infusion group $(\mathrm{n}=60)$ & P value \\
\hline Age & $53.68(9.20)$ & $54.76(8.49)$ & 0.51 \\
\hline $\begin{array}{l}\text { Gender } \\
\text { Male/Female) }\end{array}$ & $32 / 28$ & $37 / 23$ & 0.36 \\
\hline $\begin{array}{l}\text { Duration of } \\
\text { surgery (min) }\end{array}$ & $99.58(35.50)$ & $88.50(25.75)$ & 0.14 \\
\hline
\end{tabular}


Krishna et al. Sri Lankan Journal of Anaesthesiology: 27(2):110-114(2019)

Data are mean (standard deviation) for age and median (interquartile range) for duration of surgery Patients remained in the target glycaemic range for 4440 minutes out of 10680 minutes of surgery in the bolus group and 2940 minutes out of 10800 minutes of surgery in the infusion group. Patients were in the target glycaemic range for a longer period of time $(41.57 \%$ of the intraoperative period) in bolus group when compared to infusion group (27.22\% of the intraoperative period). This difference was significant $(\mathrm{P}<0.001$; Chi square test).

To see if preoperative glucose levels confounded the results, we compared the preoperative blood glucose levels between the two groups (Table 4). It is evident from the table that a greater number of patients in the bolus group were outside the target range before the start of surgery.

Table 4: Blood glucose range in patients before the start of surgery

\begin{tabular}{|l|l|l|}
\hline $\begin{array}{l}\text { Blood glucosed } \\
\text { range (mg/dL) }\end{array}$ & $\begin{array}{l}\text { Bolus group (number } \\
\text { of patients) }\end{array}$ & $\begin{array}{l}\text { nfusion group (number } \\
\text { of patients) }\end{array}$ \\
\hline $150-180$ & 10 & 17 \\
\hline $181-210$ & 14 & 35 \\
\hline $211-240$ & 11 & 6 \\
\hline $241-270$ & 15 & 1 \\
\hline $271-300$ & 4 & 0 \\
\hline$>300$ & 6 & 1 \\
\hline
\end{tabular}

Postoperative serum potassium level decreased in both the groups [from $4.34(0.55) \mathrm{mmol} / \mathrm{l}$ to $4.13(0.48) \mathrm{mmol} / \mathrm{l}$ in bolus group, $\mathrm{P}<0.001$ and from $4.29(0.48) \mathrm{mmol} / \mathrm{l}$ to $4.26(0.36) \mathrm{mmol} / \mathrm{l}$ in infusion group, $\mathrm{P}=0.54$; Data are mean (standard deviation), $\mathrm{t}$ test)] but was clinically and statistically not significant.

\section{Discussion}

An ideal blood glucose control regimen should give good glycaemic control with least incidence of hypoglycaemia. Optimal blood sugar control is essential not only in preventing untoward complications, but also reflects the quality of health care. In this regard, a simple, easy to use regimen will help in working towards these goals.

In this study, we chose to compare the proportion of patients in the target glucose levels between $100 \mathrm{mg} / \mathrm{dl}$ and $180 \mathrm{mg} / \mathrm{dl}$ and the proportion of intra-operative surgery time (in minutes) during which patient was in the target range as primary outcomes rather than comparing the absolute values of blood sugar at different time intervals to be more meaningful clinically. Insulin bolus regimen maintained the patients for longer duration of time in target glycaemic range $(41.57 \%$ of intraoperative period) as compared to infusion group (27.22\%), though there was no significant difference in the proportion of patients in the target range between both the groups. Also, we noted that though a greater number of patients were outside the target blood glucose range preoperatively in bolus group when compared to infusion group, we had better control of blood glucose with the former. This confirms the effectiveness of insulin bolus regimen in management of blood sugars during the intraoperative period, especially in patients with poor preoperative glycaemic control.

The major concern with intravenous insulin boluses is the fear of hypoglycaemia. In the group of patients that we studied, there was no hypoglycaemia with both the regimens. We also compared to see if there was any significant difference in the serum potassium levels between both the studied groups as insulin is known to cause decrease in serum potassium levels. We found that there was no significant difference between both the groups clinically, although it was statistically significant in bolus group.

Prior studies have shown varying results while comparing insulin bolus regimen with infusion regimen. ${ }^{9,14}$ But there are no studies to compare between intravenous bolus and infusion regimens in the intraoperative period.

Alberti et al and AAGBI guidelines in 2015 compared glucose control in two sets of diabetic patients and concluded that insulin infusion is a better choice in terms of glycaemic control over subcutaneous regimen. ${ }^{9,13}$ ADVANCE trial, ${ }^{10}$ study by Berghe et $\mathrm{al}^{11}$ and ACCORD study ${ }^{12}$ were conducted comparing two intravenous insulin regimens with different target ranges of blood glucose levels for the regimens. The above studies thus emphasize the effectiveness of intravenous insulin regimens with additional emphasis on the target blood glucose levels (between $100 \mathrm{mg} / \mathrm{dl}$ and $180 \mathrm{mg} / \mathrm{dl}$ ).

Our study had some limitations. Blood glucose levels were monitored only once an hour. The fluctuations within this hour could not be captured since there is no monitor for continuous glucose monitoring. The onset time of intravenous human actrapid is immediate and 
Krishna et al. Sri Lankan Journal of Anaesthesiology: 27(2):110-114(2019)

the peak effect is at 10-15 minutes. So, it is unlikely that these patients could have experienced hypoglycaemia and recovered from the same as well within one hour of monitoring. Markers of stress levels were not monitored in the study. So, despite the absence of baseline dextrose infusion in the bolus group blood glucose levels were maintained. Whether this happened at the expense of catabolism is not clear from this study. Preoperative glycaemic control was not compared between the groups using glycosylated haemoglobin levels.

\section{Conclusion}

Intravenous insulin bolus regimen as compared to insulin infusion regimen for intraoperative blood glucose management provides better glycaemic control measured in terms of proportion of intraoperative duration during which the patient remained in the target blood glucose levels. However, the proportion of patients in the target blood glucose levels was similar with both the regimens.

\section{References}

1. Galloway JA, Shuman CR: Diabetes and surgery. Am J Med 1963;34: 177-191. https://doi.org/10.1016/0002-9343(63)90052-4

2. Goldmann DR: Surgery in patients with endocrine dysfunction. Med Clin North Am 1987;71: 499-509.

https://doi.org/10.1016/S0025-7125(16)30854-9

3. Jack SD, Alberti KGMM. Management of Diabetes Mellitus in Surgical Patients. Diabetes Spectrum 2002; 15: 44 -48.

https://doi.org/10.2337/diaspect.15.1.44

4. Sudhakaran S, Surani SR. Guidelines for Perioperative Management of the Diabetic Patient. Surgery Research and Practice 2015; 2015: Article ID 284063.

https://doi.org/10.1155/2015/284063

PMid:26078998 PMCid:PMC4452499

5. Duggan EW, Carlson K, Umpierrez GE. Perioperative Hyperglycemia Management: An Update. Anesthesiology2017;126(3):547-560. https://doi.org/10.1097/ALN.0000000000001515 PMid:28121636 PMCid:PMC5309204

6. Simha V, Shah P. Perioperative Glucose Control in Patients With Diabetes Undergoing Elective Surgery. JAMA. 2019;321(4):399-400.

https://doi.org/10.1001/jama.2018.20922 PMid:30615031

7. Polderman JAW, Houweling LP, et al. Study protocol of a randomised controlled trial comparing perioperative intravenous insulin, GIK or GLP-1 treatment in diabetes-PILGRIM trial. BMC Anesthesiology 2014, 14:91. https://doi.org/10.1186/1471-2253-14-91 PMid:25419179 PMCid:PMC4240889

8. Miriam A, Korula G. A simple glucose insulin regimen for perioperative blood glucose control:
The Vellore regimen. Anesth Analg 2004; 99: $598-602$.

https://doi.org/10.1213/01.ANE.0000122824.210 65.CA

PMid: 15271748

9. Alberti KGMM, Thomas DJB. The management of diabetes during surgery. $\mathrm{Br} \mathrm{J}$ Anaesth 1979;51:693-710.

https://doi.org/10.1093/bja/51.7.693 PMid:399195

10. The ADVANCE Collaborative Group. Intensive blood glucose control and vascular outcomes in patients with type 2 diabetes. $\mathrm{N}$ Engl J Med 2008; 358:2560-2572.

https://doi.org/10.1056/NEJMoa0802987 PMid: 18539916

11. The ACCORD study group. Effects of intensive glucose lowering in type 2 diabetes. $\mathrm{N}$ Engl $\mathrm{J}$ Med 2008; 358: NO. 24.

https://doi.org/10.1056/NEJMoa0802743 PMid:18539917 PMCid:PMC4551392.

12. Association of Anaesthetists of Great Britain and Ireland. Peri-operative management of the surgical patient with diabetes 2015. Anaesthesia 2015;70: 1427-1440.

https://doi.org/10.1111/anae. 13233 PMid:26417892 PMCid:PMC5054917

13. Hemmerling TM, Schmid MC, Kern S, Jacobi KE. Comparison of a continuous glucoseinsulin-potassium infusion versus intermittent bolus application of insulin on perioperative glucose control and hormone status in insulintreated type 2 diabetics. J Clin Anesth 2001;13: 293-300.

https://doi.org/10.1016/S0952-8180(01)00276-8

14. Jacobi J, Bircher N, Krinsley J, Agus M, Braithwaite SS, Deutschman C, Freire AX, Geehan D, Kohl B, Nasraway SA, Rigby M, Sands K, Schallom L, Taylor B, Umpierrez G, Mazuski J, Schunemann H: Guidelines for the use of an insulin infusion for the management of hyperglycemia in critically ill patients. Crit Care Med 2012; 40:3251-76 https://doi.org/10.1097/CCM.0b013e3182653269 PMid:23164767 